\title{
A titration model for evaluating calcium hydroxide removal techniques
}

\author{
Mark PHILLIPS ${ }^{1}$, Scott McCLANAHAN², Walter BOWLES ${ }^{2}$ \\ 1- Private practice, Duluth, MN, USA. \\ 2- Division of Endodontics, University of Minnesota School of Dentistry, Minneapolis, MN, USA. \\ Corresponding address: Walter Bowles - Division of Endodontics - University of Minnesota School of Dentistry - 8-166 Moos Tower, 515 Delaware St SE - \\ Minneapolis, MN 55455 - Phone: 612-624-9613 - Fax: 612-624-7960 - e-mail: bowle001@umn.edu
}

Submitted: November 3, 2014 - Modification: December 12, 2014 - Accepted: December 17, 2014

ABSTRACT

bjective: Calcium hydroxide $\left(\mathrm{Ca}(\mathrm{OH})_{2}\right)$ has been used in endodontics as an intracanal
medicament due to its antimicrobial effects and its ability to inactivate bacterial
endotoxin. The inability to totally remove this intracanal medicament from the root canal
system, however, may interfere with the setting of eugenol-based sealers or inhibit bonding
of resin to dentin, thus presenting clinical challenges with endodontic treatment. This study
used a chemical titration method to measure residual $\mathrm{Ca}(\mathrm{OH})_{2}$ left after different endodontic
irrigation methods. Material and Methods: Eighty-six human canine roots were prepared
for obturation. Thirty teeth were filled with known but different amounts of $\mathrm{Ca}(\mathrm{OH})_{2}$ for 7
days, which were dissolved out and titrated to quantitate the residual $\mathrm{Ca}(\mathrm{OH})_{2}$ recovered
from each root to produce a standard curve. Forty-eight of the remaining teeth were filled
with equal amounts of $\mathrm{Ca}(\mathrm{OH})_{2}$ followed by gross $\mathrm{Ca}(\mathrm{OH})_{2}$ removal using hand files and
randomized treatment of either: 1 ) Syringe irrigation; 2$)$ Syringe irrigation with use of an
apical file; 3 ) Syringe irrigation with added 30 s of passive ultrasonic irrigation (PUI), or 4 )
Syringe irrigation with apical file and $\mathrm{PUI}(\mathrm{n}=12 / \mathrm{group})$. Residual Ca(OH) was dissolved
with glycerin and titrated to measure residual $\mathrm{Ca}(\mathrm{OH})_{2}$ left in the root. Results: No method
completely removed all residual $\mathrm{Ca}(\mathrm{OH})_{2}$. The addition of $30 \mathrm{~s}$ PUI with or without apical file
use removed $\mathrm{Ca}(\mathrm{OH})_{2}$ significantly better than irrigation alone. Conclusions: This technique
allowed quantification of residual $\mathrm{Ca}(\mathrm{OH})_{2}$. The use of PUI (with or without apical file)
resulted in significantly lower $\mathrm{Ca}(\mathrm{OH})_{2}$ residue compared to irrigation alone.

Keywords: Calcium hydroxide. Ultrasonic therapy. Glycerin. Therapeutic irrigation.

\section{INTRODUCTION}

Calcium hydroxide $\left(\mathrm{Ca}(\mathrm{OH})_{2}\right)$ as an intracanal medicament (ICM) has been extensively studied and its clinical use well established $3,17,23-26$. In aqueous solution $\mathrm{Ca}(\mathrm{OH})_{2}$ dissociates into calcium and hydroxyl ions. The large amount of hydroxyl ions liberated interferes with the bacterial cytoplasmic membrane integrity, largely by interruption of transfer of nutrients and destruction of phospholipids from unsaturated fatty acids ${ }^{10}$.

In vitro studies have demonstrated potential clinical concerns regarding the inability to fully remove calcium hydroxide. Residual $\mathrm{Ca}(\mathrm{OH})_{2}$ may interfere with sealer entrance into dentinal tubules and inhibit bonding of resin to dentin ${ }^{6}$. Additionally, leakage may be increased with the use of calcium hydroxide as an $\mathrm{ICM}^{13,14}$ or residual $\mathrm{Ca}(\mathrm{OH})_{2}$ may interfere with the setting of eugenol based sealers or MTA $^{19,27}$.

A variety of $\mathrm{Ca}(\mathrm{OH})_{2}$ removal techniques have been studied. Irrigation-only techniques appear to result in poor $\mathrm{Ca}(\mathrm{OH})_{2}$ removal ${ }^{15}$, while use of a master apical file or passive ultrasonic irrigation (PUI) for $\mathrm{Ca}(\mathrm{OH})_{2}$ removal have been found efficacious ${ }^{12,22,28}$. For review of PUI, see van der Sluise, et al. ${ }^{29}$ (2007). Quantification of residual $\mathrm{Ca}(\mathrm{OH})_{2}$ remaining in the root has been attempted by using digital images $4,8,12,22$, while nonparametric grading systems have been used with digital photographic images in teeth with premade grooves ${ }^{11,30}$. Concerns exist, however, regarding two-dimensional quantification on a nonplanar surface and the inability to differentiate 
debris vs. $\mathrm{Ca}(\mathrm{OH})_{2}$. More recently, spiral $\mathrm{CT}^{20}$ and micro CT have been used to study calcium hydroxide removal ${ }^{31}$. These studies are all problematic in that they cannot accurately detect residual $\mathrm{Ca}(\mathrm{OH})_{2}$ in actual teeth.

The technique proposed by Bramante allows reuse of specimens, and thus reduces inaccuracies due to different specimen anatomy ${ }^{5}$. With reuse of the same specimens, however, cumulative effects of the chelating agent EDTA can occur and removal of residual $\mathrm{Ca}(\mathrm{OH})_{2}$ cannot be confirmed. Teeth used in this study had a standardized canal preparation and were only used once.

Visual identification of residual $\mathrm{Ca}(\mathrm{OH})_{2}$, even with SEM, is not accurate. Since $\mathrm{Ca}(\mathrm{OH})_{2}$ has a high $\mathrm{pH}(\mathrm{pH}>12)$, this attribute may be used to identify residual $\mathrm{Ca}(\mathrm{OH})_{2}$ left in the root canal system by $\mathrm{pH}$ determination of known amounts retrieved from the canal compared to unknown amounts in canals after various irrigation methods have been used. The purpose of this study was to employ a chemical microtitration technique to test removal methods of $\mathrm{Ca}(\mathrm{OH})_{2}$ paste (Calasept ${ }^{\circledR}$; JB Dental, Ridgefield, Connecticut, USA) from the root canal system.

\section{MATERIAL AND METHODS}

This study was exempted by the Institutional Review Board of the University. Eighty-six extracted single canal maxillary and mandibular canines were stored in normal saline with $0.2 \%$ sodium azide. Samples were randomized into groups. Three teeth served as positive controls and three as negative controls. Thirty teeth served as standards.

\section{Preparation of specimens}

Teeth were decoronated at the cementoenamel junction and radiographed from the proximal and buccal view. The Pruett, Clement, and Carnes method was used to standardize curvature at $\leq 15^{021}$. Two samples were excluded due to aberrant anatomy. Root length was standardized at $17.5 \mathrm{~mm}$. A glide path was established to a \#25 Flex-O hand file (Dentsply-Maillefer, Johnson City, Tennessee, USA) and K3 nitinol files (SybronEndo, Cuyahoga Falls, Ohio, USA) were used to prepare each tooth according to manufacturers' recommendations to a 50/0.06 final apical file (FAF). Patency was established with size 20 Flex-O file. Irrigation with $1 \mathrm{~mL}$ of $\mathrm{NaOCl} 5.25 \%$ and recapitulation was performed between files. The length of the Max-iprobe (Dentsply, Elgin, Illinois, USA) was set at 2 $\mathrm{mm}$ from the working length (WL). Thirty seconds of passive ultrasonic irrigation with $5.25 \% \mathrm{NaOCl}$ was performed with a one minute soak using 17\% EDTA to remove smear layer. A final $3 \mathrm{~mL}$ rinse of $5.2 \%$ $\mathrm{NaOCl}$ was performed and all canals were dried with paper points. Canals were then filled with Calasept ${ }^{\circledR}$
$\left[\mathrm{Ca}(\mathrm{OH})_{2}\right.$ based ICM] by inserting the syringe tip until locked in, then loosening and backfilling. Radiographs confirmed a dense $\mathrm{Ca}(\mathrm{OH})_{2}$ fill. Teeth were temporized with Fuji IX resin modified glass ionomer (GC Corporation, Tokyo, Japan) and placed in an incubator (Precision Scientific, Chennai, India) at $37^{\circ} \mathrm{C}$ for one week in a humid environment.

\section{Standards}

In order to develop a standard curve using known amounts of $\mathrm{Ca}(\mathrm{OH})_{2}$, thirty teeth were selected. The identical radiographic and the preparation protocol were utilized for the standard teeth and for unknown samples, except that different known weights of $\mathrm{Ca}(\mathrm{OH})_{2}$, were added to the teeth (much smaller weights to replicate residual $\mathrm{Ca}(\mathrm{OH})_{2}$ after irrigation methods). After temporization and 7 days of incubation, the glycerin transfer and titration steps were performed in identical fashion to samples. A standard curve was generated by graphing the different known weights added to the teeth versus the $\mathrm{pH}$ recording after addition of known micromoles of HCL. Samples were titrated using $0.025,0.05,0.1,0.5,1$, or $3 \mathrm{M} \mathrm{HCL}$ with 10 microliter aliquots using a micropipette. Usually titrations began with 10 microliters of $0.1 \mathrm{M}$. If the initial $\mathrm{pH}$ was higher, the operator may have used a higher molarity such as $0.2 \mathrm{M}$. If the initial $\mathrm{pH}$ of the mixture was lower (i.e. 11.0-11.4), the operator may have begun with a weaker concentration (i.e. $0.05 \mathrm{M} \mathrm{HCL}$ ). $\mathrm{pH}$ measurements were recorded after each addition of HCL using a model HO4N-0001 micro $\mathrm{pH}$ electrode (Lazar Research Laboratories, Los Angeles, California, USA) and a Model $60 \mathrm{pH}$ meter (Lazar Research Laboratories, Los Angeles, California, USA). After each aliquot addition of acid to the microcentrifuge tube, the tube was vortexed for $10 \mathrm{~s}$. Adequate time was given for each $\mathrm{pH}$ measurement - this was approximately $10-60 \mathrm{~s}$ for the meter to equalize.

After creating a titration curve for each sample, linear regression was applied to each curve. The neutral point, $\mathrm{pH}=7$, was selected for use in each regression curve. By solving for $\mathrm{pH}=7$, cumulative micromoles of $\mathrm{HCL}$ added could be determined for each titration.

A second standard curve was calculated using only $\mathrm{Ca}(\mathrm{OH})_{2}$ in microcentrifuge tubes and not placed in teeth. In the second standard curve, small amounts of Calasept ${ }^{\circledR}$ was added to preweighed empty microcentrifuge tubes. Eleven different $\mathrm{Ca}(\mathrm{OH})_{2}$ weights were made in triplicate and used to produce the standard curve. 100 microliters of $60 \%$ glycerin at $40^{\circ} \mathrm{C}$ was added to each microcentrifuge tube and vortexed for $30 \mathrm{~s}$ to ensure full dissolution of the small amount of $\mathrm{Ca}(\mathrm{OH})_{2}$, with $\mathrm{HCL}$ titration and $\mathrm{pH}$ measurements completed. 


\section{Treatment groups}

Samples were removed from incubator and temporary fillings removed. For each group (48 teeth; $n=12$ /group), a \#30 Flex-O file and a \#50 Flex-O file were used for gross removal of Calasept ${ }^{\circledR}$ before each irrigation technique: Group 1: Irrigation ( $\mathrm{NaOCl} 5.2 \% 3 \mathrm{~mL}$ followed by EDTA $17 \% 3 \mathrm{~mL}$. A final rinse of $\mathrm{NaOCl} 5.2 \% 5 \mathrm{~mL}$ was performed). Group 2: Irrigation (as in group 1) with the addition of a K3 \#50-0.06 taper instrumented to WL between the first two rinses. Group 3: Irrigation (as in group 1) with the use of PUI for $30 \mathrm{~s}$ between the first $\mathrm{NaOCl}$ and EDTA rinse. Group 4: consisted of $\mathrm{NaOCl}$ $5.2 \% 1.5 \mathrm{~mL}$, use of a $\mathrm{K} 3$ \#50-0.06 instrumented to WL, $1.5 \mathrm{~mL} \mathrm{NaOCl}, 30 \mathrm{~s}$ of PUI, and the final EDTA and $\mathrm{NaOCl}$ rinses as in previous groups.

Three teeth were selected for negative controls. These teeth were instrumented but canals were left empty. Negative control teeth were included in the experimental sample set and operator was also blinded to control teeth. Positive controls consisted of three microcentrifuge tubes with saturated solutions of $\mathrm{Ca}(\mathrm{OH})_{2}$.

\section{Removal of residual calcium hydroxide}

Any residual $\mathrm{Ca}(\mathrm{OH})$, remaining in the tooth after gross $\mathrm{Ca}(\mathrm{OH})_{2}$ removal was removed by the following manner: a preparation of $60 \%$ glycerin (Humco Corporation, Texarkana, TX): 40\% distilled water at $40^{\circ} \mathrm{C}$ was placed into the canal with a Ultradent capillary tip (Ultradent Products, Inc., South Jordon, Utah, USA). PUI for $10 \mathrm{~s}$ was performed with a \#15 Zipperer file (Roydent, Rochester Hills, Minnesota, USA) at $2 \mathrm{~mm}$ from
WL to help the remaining Calasept ${ }^{\circledR}$ dissolve. The glycerin with dissolved $\mathrm{Ca}(\mathrm{OH})_{2}$ was removed using a narrow Ultradent tip and a $10 \mathrm{~mL}$ syringe, with the aliquots placed into a $1.5 \mathrm{~mL}$ microcentrifuge tube (Fisher Scientific, Pittsburgh, Pennsylvania, USA). Aliquots were repeated until 100 microliters was obtained.

A single calibrated 20 microliter Pipetman micropipette (Gilson Inc., Middleton, Wisconsin, USA) was used for all titrations. Each microcentrifuge tube was labeled with a second random number to blind the operator. A titration curve was generated by adding 10 microliter aliquots of $0.025,0.05$, $0.1,0.5,1$, or $3 \mathrm{M} \mathrm{HCL}$ using a micropipette. To ensure a good mix, each microcentrifuge tube was vortexed with a Vortex Genie Mixer (Scientific Products, Evanston, Illinois, USA) for $10 \mathrm{~s}$ between additions and heated to $40^{\circ} \mathrm{C} \pm 1^{\circ}$ in a Hanau ${ }^{\circledR}$ low temperature water bath (Teledyne Water Pick, Fort Collins, Colorado, USA). $\mathrm{pH}$ measurements were recorded after each addition of $\mathrm{HCL}$ using a model HO4N-0001 semi-micro pH electrode (Lazar Research Laboratories, Los Angeles, California, USA) and a Model $60 \mathrm{pH}$ meter (Lazar Research Laboratories, Los Angeles, California, USA). Based on pilot studies, an algorithm describing which molarity to add based on the current $\mathrm{pH}$ was made. The micro $\mathrm{pH}$ electrode and meter were calibrated with standard $\mathrm{pH}$ solutions (Omega Scientific, Tarzana, California, USA). After each pH measurement, the tip of the electrode probe was thoroughly rinsed with distilled water and wiped with a Kim Wipe ${ }^{\circledR}$ (Kimberley-Clark Professional, Mississauga, Ontario, $\mathrm{CA})$. All $\mathrm{pH}$ readings were

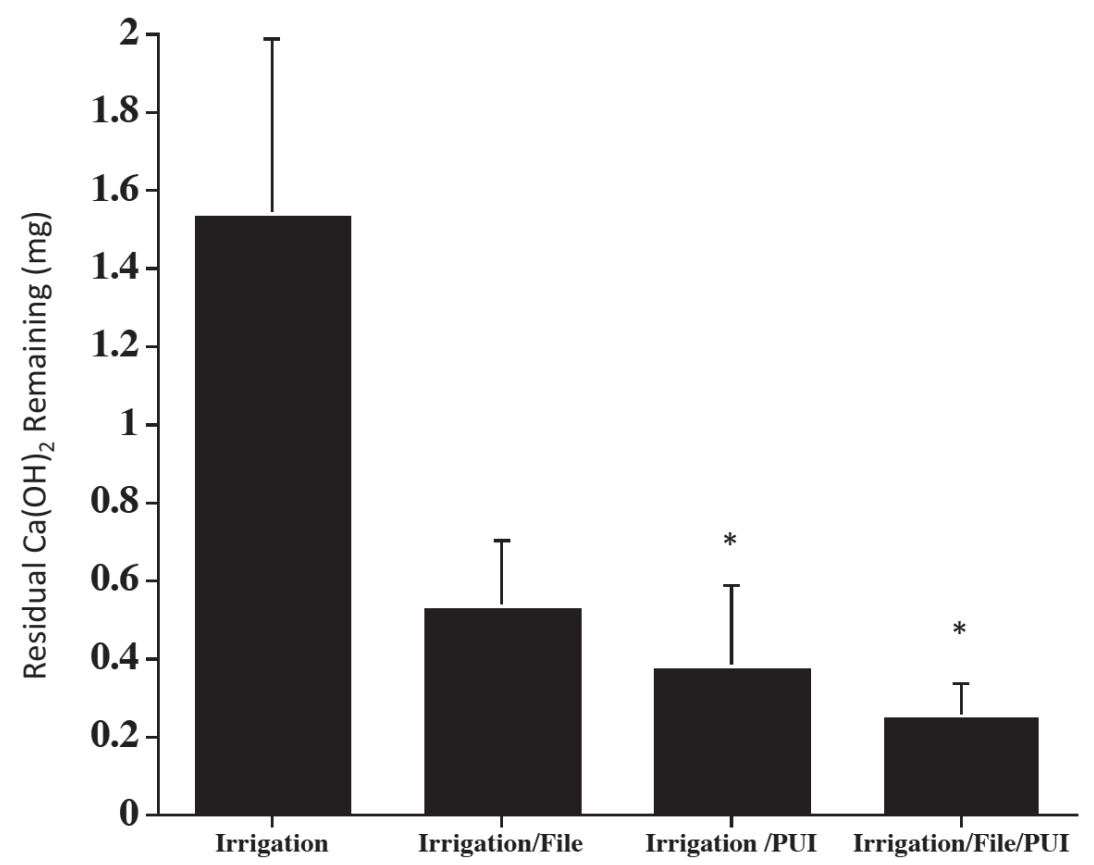

Figure 1- Residual calcium hydroxide remaining after each removal technique (means \pm S.E.M.). ${ }^{*} p<0.05$ compared to "Irrigation Only" group. PUI=passive ultrasonic irrigation 
recorded. The chemical reaction between $\mathrm{Ca}(\mathrm{OH})_{2}$ and $\mathrm{HCL}$ is described by the equation: $2 \mathrm{HCl}+$ $\mathrm{Ca}(\mathrm{OH})_{2} \rightarrow \mathrm{CaCl}_{2}+2 \mathrm{H}_{2} \mathrm{O}^{7}$.

Standard deviations and means were calculated for each group, and pairwise comparisons were made using a Tukey-Kramer multiple comparisons adjustment.
After the experiment, several representative teeth were split and SEM (Model TM3000 Table Top Microscope, Hitachi High-Technologies Corporation, Tokyo, Japan) was performed to visually assess the inside canal surface.

Standard Titration Curve for Known Amounts of $\mathrm{Ca}(\mathrm{OH})_{2}$

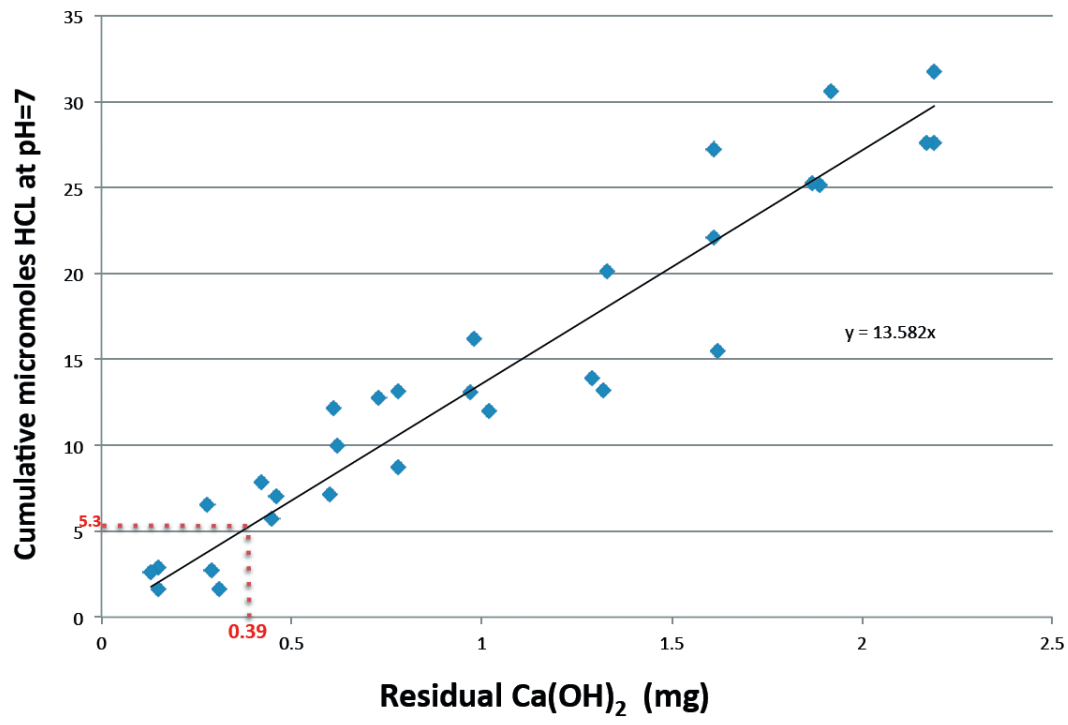

Figure 2- Sample standard curve. Cumulative $\mu$ moles of $\mathrm{HCL}$ at $\mathrm{pH}=7$ for each standard was plotted against initial known weights $(\mathrm{mg})$ of $\mathrm{Ca}(\mathrm{OH})_{2}$. For example, the vertical red dotted line indicates that $0.39 \mathrm{mg}$ of $\mathrm{Ca}(\mathrm{OH})_{2}$ standard would take $5.3 \mu$ moles of $\mathrm{HCL}$ to reach $\mathrm{pH}=7.0$ (horizontal red dotted line). Using these standard known amounts, we can create a linear regression line to determine the amounts of $\mathrm{Ca}(\mathrm{OH})_{2}$ in our unknown samples by the umoles of HCL used to get to $\mathrm{pH}=7.0$

Titration of One Known Unknown $\mathrm{Ca}(\mathrm{OH})_{2}$ Amount

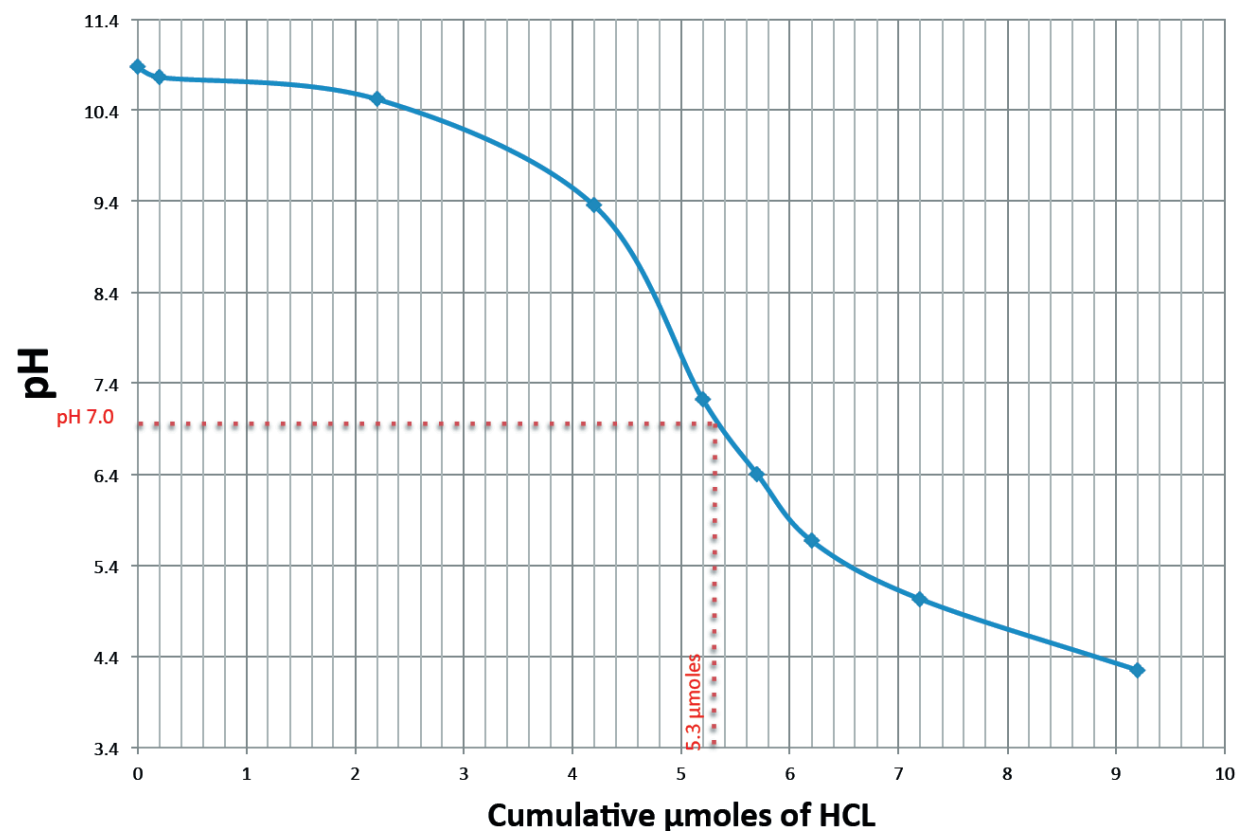

Figure 3- A titration curve was made from utilizing data points for an unknown sample titrated with HCL to pH 7.0. From the $\mu$ moles used at $\mathrm{pH} 7.0$, we can determine the amount $\mathrm{Ca}(\mathrm{OH})_{2}$ in our sample using the standard curve in Figure 2 


\section{RESULTS}

Figure 1 shows the means and standard deviations of residual calcium hydroxide after the various removal group techniques were applied. The groups differed significantly $[F(3,42)=4.47$, $\mathrm{p}=0.0082]$, indicating that there was a difference between the group means. The group 1 (irrigation only) mean was significantly different than the means of groups 3 (PUI) and 4 (PUI + file), $p=0.0291$ and $p=0.0104$, respectively. No other comparisons were statistically significant. Negative controls [no $\mathrm{Ca}(\mathrm{OH})_{2}$ added] were found to have near neutral $\mathrm{pH}$ measurements, while positive controls [fully $\mathrm{Ca}(\mathrm{OH})_{2}$ saturated $100 \mu \mathrm{L}$ of glycerin] required larger amounts of HCL to achieve neutrality.

A standard curve is illustrated in Figure 2. An example of a titration of one of the unknown samples and the corresponding linear regression line and equation is shown in Figure 3 . The dotted red line shows that at $\mathrm{pH} 7.0$, it took 5.3 umoles
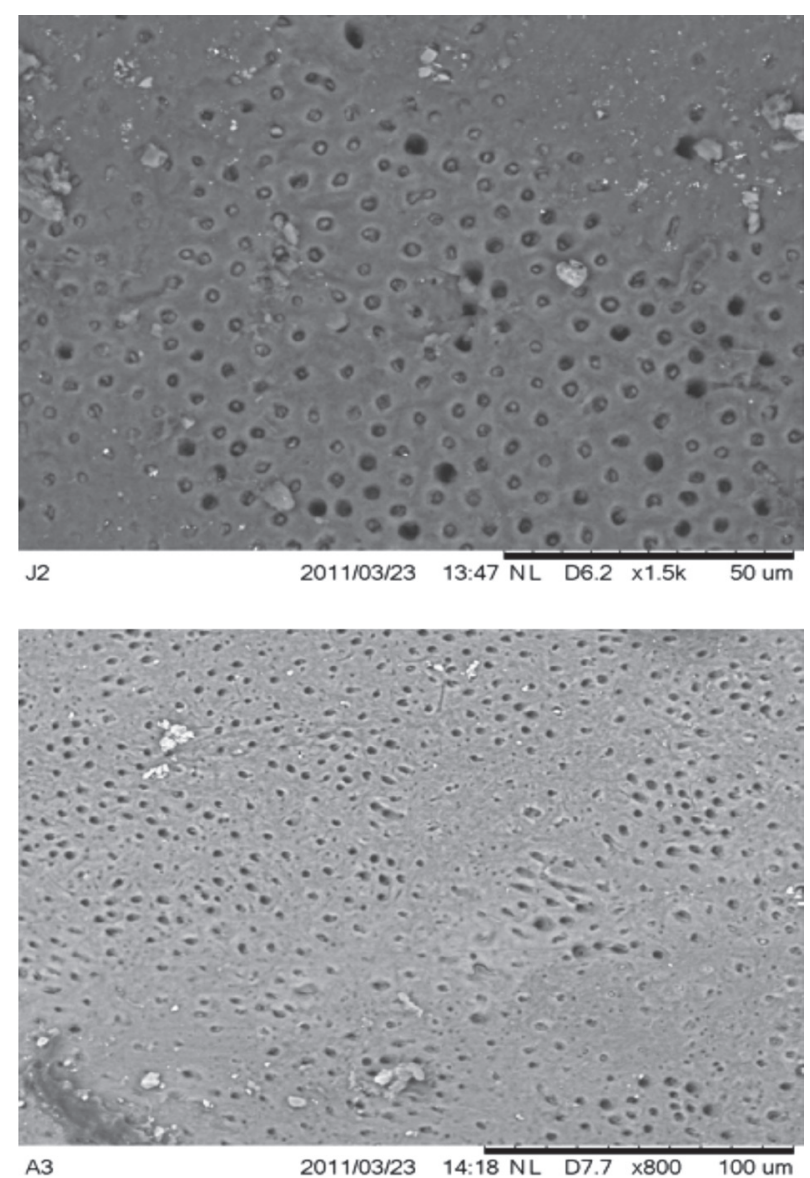

Figure 4- After the irrigation experiment, several teeth were split and scanning electron microscopy (SEM) (Model TM3000 Table Top Microscope, Hitachi HighTechnologies Corporation, Tokyo, Japan) was performed to visually access the tooth surface. Representative micrographs of the apical one-third of different roots are shown at $1,500 \mathrm{X}$ (top) or $800 \mathrm{X}$ (bottom) of $\mathrm{HCL}$ to neutralize this sample. Based on the standard curve of known samples in Figure 2, we can determine from the $\mu$ moles of HCL exactly how much $\mathrm{Ca}(\mathrm{OH})_{2}$ was present in the sample [in this case using the $y=13.582 x$ linear regression formula, we now know $y=5.3$ and can solve for $x$ as $0.39 \mathrm{mg}$ of $\mathrm{Ca}(\mathrm{OH})_{2}$ in the unknown sample].

Examination of SEM's taken after our study revealed some debris mixed in with the glycerin (see Figure 4).

\section{DISCUSSION}

This study found agreement with previous studies that no $\mathrm{Ca}(\mathrm{OH})$, removal technique successfully removed all the calcium hydroxide from the canal system $12,16,20,28$. This may pose a clinical problem since residual calcium hydroxide interacts with eugenol in ZOE based sealers, leading to residual eugenol in the set product ${ }^{19}$. Thus $\mathrm{Ca}(\mathrm{OH})_{2}$ may interfere with the obturation seal. The clinical implication of unset sealer is unclear and further clinical studies are needed to elucidate the effect of this interaction. Examination of SEMs taken after our study revealed some debris mixed in with the glycerin in the open canal. Perhaps the glycerin transfer failed to remove all the Calasept ${ }^{\circledR}$, or the glycerin transfer did remove all the Calasept ${ }^{\circledR}$, and what was seen mixed in with the remaining glycerin was actually dentinal debris. As part of the methods used in this experiment, collection of residual $\mathrm{Ca}(\mathrm{OH})_{2}$ included passive ultrasonic instrumentation between each transfer. This was done to ensure the $\mathrm{Ca}(\mathrm{OH})_{2}$ on the walls was incorporated into solution, and likely would have also incorporated more debris into the glycerin. One method to differentiate residual debris from Calasept ${ }^{\circledR}$ would be to radiolabel Calasept ${ }^{\circledR}$ and apply removal studies, which was not performed in this study. Then an autoradiographic analysis could be performed to determine "what we are actually looking at" after calcium hydroxide removal methods. Allison, et al. ${ }^{1}$ (1979) used such a technique with ${ }^{45} \mathrm{Ca}$ to prove that step back preparations had less leakage than serial preparation. It appears that some $\mathrm{Ca}(\mathrm{OH})_{2}$ is left in the canal during most irrigation methods, mainly in the dentinal tubules, but amounts of residual $\mathrm{Ca}(\mathrm{OH})_{2}$ in the open canal could be minimized using passive ultrasonic instrumentation. Removal of medicament trapped within the dentinal tubules was attempted with repeated dissolution using glycerin extracts and passive ultrasonic irrigation in the same root, but could not be removed. The results here are for comparative purposes, and demonstrate that even with ideal conditions and access (decoronated tooth, straight root), medicament still remains in the canal. This may interfere with the setting of eugenol based 
sealers or $\mathrm{MTA}^{19,27}$.

One primary result of our study was that the 30 s use PUI (groups 3 and 4) produced better $\mathrm{Ca}(\mathrm{OH})_{2}$ removal than the irrigation-only group. This is in agreement with many studies supporting the effectiveness of PUI ${ }^{4,9,12,30,31}$. However, Lev, et al.18 (1987) found contrasting results in that 1 minute of passive ultrasonic step back was not significantly better in debris removal than irrigation and hand filing alone. The $30 \mathrm{~s}$ time frame was adequate to achieve statistical significance. This is in contrast to a study that examined debris removal after a 3 minute PUI time per canals (12 minutes per molar) ${ }^{2}$. Another study utilizing sequential micro-CT scans studied $\mathrm{Ca}(\mathrm{OH})_{2}$, removal with PUI activation for 60 seconds per canal ( 4 minutes per molar) ${ }^{31}$. Our results demonstrated two minutes (30 s per canal) of PUI for a typical four canal molar is adequate to remove most residual $\mathrm{Ca}(\mathrm{OH})_{2}$ from the root canal. This is in agreement with Sabins, et al. ${ }^{22}$ (2003) who found $30 \mathrm{~s}$ of PUI adequate to significantly reduce debris levels in the mesial canals of mandibular molars ${ }^{22}$.

The agreement of our titration model with previous pixel or voxel-quantification studies confirms the accuracy of this technique for evaluating residual $\mathrm{Ca}(\mathrm{OH})_{2}$ in the canal. This is very significant in that to our knowledge chemical quantification of residual calcium hydroxide has never been performed. In contrast, pixelquantification methods examine debris and $\mathrm{Ca}(\mathrm{OH})_{2}$ and, while they share many advantages, they also have limitations. Some potential issues with pixelquantification methods include concerns with reuse of teeth for repeated testing. Another concern is the need for very uniform canals - necessary so that teeth can be predictably split. One $\mathrm{Ca}(\mathrm{OH})_{2}$ removal study used mesial mandibular molar canals for uniformity in canal morphology ${ }^{12}$. While standard preparation of canals was a part of this study, this measurement technique does not strictly require uniform canals. A titration technique, such as this, might be useful to evaluate $\mathrm{Ca}(\mathrm{OH})_{2}$, removal from the more variable-sized distal canal or C-shaped canals. In a clinical setting, non-uniform canals may benefit the most from PUI.

A titration-quantification method differs from a voxel or pixel quantification method in that the former expresses results with a single value. A pixel or voxel-quantification method can give results in terms of location of remaining debris or $\mathrm{Ca}(\mathrm{OH})_{2}$, while a chemical quantification method gives a number for the entire canal. This may be a disadvantage for a titration technique in that it may be more important to define $\mathrm{Ca}(\mathrm{OH})_{2}$ removal specifically in one area, such as the apical one-third. It is interesting to note a titration technique gives results in $\mathrm{mg}$ of remaining $\mathrm{Ca}(\mathrm{OH})_{2}$. Most studies express results in percent, rather than actual weight of $\mathrm{Ca}(\mathrm{OH})_{2}$.

The titration technique is time consuming. Also, the $\mathrm{Ca}(\mathrm{OH})_{2}$ studied must be soluble in glycerin (or another solvent that can be titrated). Pilot studies indicated that Ultracal (Optident Ltd, International Develop Centre, West Yorkshire, UK) did not dissolve in glycerin. Further studies testing other solvents will allow more premixed $\mathrm{Ca}(\mathrm{OH})_{2}$, pastes to be studied with a chemical titration method.

\section{CONCLUSION}

This study tested a new approach to quantification of residual $\mathrm{Ca}(\mathrm{OH})_{2}$, by chemical microtitration. This model is novel and appears to be accurate and reliable, with several potential advantages. Adjuncts to irrigation such as PUI for $30 \mathrm{~s}$ or the use of a final apical file were shown to improve $\mathrm{Ca}(\mathrm{OH})_{2}$ removal from the open canal, within decoronated teeth with single straight canals, however the medicament was not fully removed from all teeth. Further studies utilizing the chemical titration method may help us understand residual $\mathrm{Ca}(\mathrm{OH})_{2}$ removal from diverse tooth types such as $\mathrm{C}$-shaped molars and wide oval shaped canals.

\section{ACKNOWLEDGEMENT}

The authors deny any conflicts of interest and any financial affiliations related to this study or its sponsors.

\section{REFERENCES}

1- Allison DS, Weber CR, Walton RE. The influence of the method of canal preparation on the quality of apical and coronal obturation. J Endod. 1979;5(10):298-304

2- Archer R, Reader A, Nist R, Beck M, Meyers W. An in vivo evaluation of the efficacy of ultrasound after step-back preparation in mandibular molars. J Endod. 1992;18(11):549-52.

3- Baik EJ, Kum KY, Yun CH, Lee JK, Lee K, Kim KK, et al. Calcium hydroxide inactivates lipoteichoic acid from Enterococcus faecalis. J Endod. 2008;34(11):1355-9.

4- Balvedi RP, Versiani MA, Manna FF, Biffi JC. A comparison of two techniques for the removal of calcium hydroxide from root canals. Int Endod J. 2010;43:763-8.

5- Bramante CM, Berbert A, Borges RP. A methodology for evaluation of root canal instrumentation. J Endod. 1987;13(5):243-5.

6- Calt S, Serper A. Dentinal tubule penetration of root canal sealers after root canal dressing with calcium hydroxide. J Endod. $1999 ; 25(6): 431-3$.

7- Cohen F, Lasfargues J]. Quantitative chemical study of root canal preparations with calcium hydroxide. Endod Dent Traumatol. 1988;4:108-13.

8- Crumpton BJ, Goodell GG, McClanahan SB. Effects on smear layer and debris removal with varying volumes of $17 \%$ REDTA after rotary instrumentation. J Endod. 2005;31(7):536-8.

9- Cunningham WT, Martin H. A scanning electron microscope evaluation of root canal débridement with the endosonic ultrasonic synergistic system. Oral Surg Oral Med Oral Pathol. $1982 ; 53(5): 527-31$. 
10- Estrela C, Sydney GB, Bammann LL, Felippe O Jr. Mechanism of action of calcium and hydroxyl ions of calcium hydroxide on tissue and bacteria. Braz Dent J. 1995;6:85-90.

11- Jiang LM, Verhaagen B, Versluis M, Langedijk J, Wesselink $P$, van der Sluis LW. The influence of the ultrasonic intensity of the cleaning efficacy of passive ultrasonic irrigation. J Endod. 2011;37(5):688-92.

12- Kenee DM, Allemang JD, Johnson JD, Hellstein J, Nichol BK. A quantitative assessment of efficacy of various calcium hydroxide removal techniques. J Endod. 2006;32(6):563-5.

13- Kim SK, Kim YO. Influence of calcium hydroxide intracanal medication on apical seal. Int Endod J. 2002;35(7):623-8.

14- Kontakiotis EG, Wu MK, Wesselink PR. Effect of calcium hydroxide dressing on seal of permanent root filling. Endod Dent Traumatol. 1997;13:281-4.

15- Lambrianidis T, Kosti E, Boutsioukis C, Mazinis M. Removal efficacy of various calcium hydroxide/chlorhexidine medicaments from the root canal. Int Endod J. 2006;39(1):55-61.

16- Lambrianidis T, Margelos J, Beltes P. Removal efficacy of calcium hydroxide dressing from the root canal. J Endod. 1999;25(2):85-8.

17- Law A, Messer H. An evidence-based analysis of the antibacterial effectiveness of intracanal medicaments. J Endod. 2004;30(10):689-94.

18- Lev R, Reader A, Beck M, Meyers W. An in vitro comparison of the step-back technique versus a step-back/ultrasonic technique for 1 and 3 minutes. J Endod. 1987;13(11):523-30.

19- Margelos J, Eliades G, Verdelis C, Palaghias G. Interaction of calcium hydroxide with zinc oxide-eugenol type sealers: a potential clinical problem. J Endod. 1997;23(1):43-8.

20- Nandini S, Velmurugan N, Kandaswamy D. Removal efficiency of calcium hydroxide intracanal medicament with two calcium chelators: volumetric analysis using spiral $\mathrm{CT}$, an in vitro study. J Endod. 2006;32(11):1097-101.

21- Pruett JP, Clement DJ, Carnes DL Jr. Cyclic fatigue testing of nickel-titanium endodontic instrument. J Endod. 1997;23(2):7785.
22- Sabins RA, Johnson JD, Hellstein JW. A comparison of the cleaning efficacy of short-term sonic and ultrasonic passive irrigation after hand instrumentation in molar root canals. J Endod. 2003;29(10):674-8.

23- Safavi KE, Nichols FC. Effect of calcium hydroxide on bacterial lipopolysaccharide. J Endod. 1993;19(2):76-8.

24- Silva LA, Nelson-Filho P, Leonardo MR, Rossi MA, Pansani CA. Effect of calcium hydroxide on bacterial endotoxin in vivo. J Endod. 2002;28(2):94-8.

25- Siquiera JF, Lopes HP. Mechanisms of antimicrobial activity of calcium hydroxide: a critical review. Int Endod J. 1999;32(5):3619.

26- Souza CA, Teles RP, Souto R, Chaves MA, Colombo AP. Endodontic therapy associated with calcium hydroxide as an intracanal dressing: microbiologic evaluation by the checkerboard DNA-DNA hybridization technique. J Endod. 2005;31(2):79-83.

27- Stefopoulos S, Tsatsas DV, Kerezooudis NP, Eliades G. Comparative in vitro study of the sealing efficiency of white vs grey ProRoot mineral trioxide aggregate formulas as apical barriers. Dent Traumatol. 2008;24(2):207-13.

28- Taşdemir T, Celik D, Er K, Yildirim T, Ceyhanil KT, Yeşilyurt C. Efficacy of several techniques for the removal of calcium hydroxide medicament from root canals. Int Endod J. 2011;44(6):505-9.

29- Van der Sluis LW, Versluis M, Wu MK, Wesselink PR. Passive ultrasonic irrigation of the root canal: a review of the literature. Int Endod J. 2007;40(6):415-26.

30- Van der Sluis LW, Wu MK, Wesselink PR. The evaluation of removal of calcium hydroxide paste from an artificial standardized groove in the apical root canal using different irrigation methodologies. Int Endod J. 2007;40(1):52-7.

31- Wiseman A, Cox TC, Paranjpe A, Flake NM, Cohenca N, Johnson JD. Efficacy of sonic and ultrasonic activation for removal of calcium hydroxide from mesial canals of mandibular molars: a microtomographic study. J Endod. 2011;37(2):235-8. 